\title{
PENGARUH PELABURAN AMONIUM HIDROKSIDA TERHADAP EMISI FORMALDEHIDA KAYU LAPIS DAN PAPAN PARTIKEL
}

\author{
Adi Santoso $^{1 *}$, Adi Yuwono ${ }^{2}$, A. R. M. Renwarin ${ }^{2}$ dan Paribotro Sutigno ${ }^{3}$ \\ ${ }^{1 *}$ Puslitbang Hasil Hutan Bogor, ${ }^{2}$ Universitas Cenderawasih \\ ${ }^{3}$ Asosiasi Panel Kayu Indonesia (APKINDO) \\ e-mail: Adisant04@yahoo.com
}

\begin{abstract}
The effect of spreading by ammonium hydroxide on formaldehyde emission of plywood and particleboard
\end{abstract}

\begin{abstract}
The formaldehyde emmision from panel products such as plywood and particleboard bonded with urea formaldehyde $(U F)$ can have negative effects to human health, especially if used in a room with limited ventilation. To reduce formaldehyde emission, chemical agents can be applied to the product. In this exsperiment report, the effect of ammonium hydroxide 25\% application on formaldehyde emission of UF on to wards the bonded plywood and particleboard was described. Application of ammonium hydroxide on plywood and particleboard significantly affected UF emission. The higher amount of application of ammonium hydroxide, the lower formaldehyde emission from plywod and particleboard. The effect of ammonium hydroxide to UF emission level differed according to type of panel and examination standard. Application of ammonium hydroxide of 0.009 $\mathrm{ml} / \mathrm{cm}^{2}$ and $0.015 \mathrm{ml} / \mathrm{cm}^{2}$, the formaldehyde emission of plywood and particleboard could meet Japanese Standard; while spreading on particleboard of $0,003 \mathrm{ml} / \mathrm{cm}^{2}$ and on plywood of $0,014 \mathrm{ml} / \mathrm{cm}^{2}$, the formaldehyde emission could conform to American Standard.
\end{abstract}

Key words : Plywood, particleboard, formaldehyde emission, spreading, ammonium hydroxide

\begin{abstract}
ABSTRAK
Emisi formaldehida dari produk panel seperti kayu lapis dan papan partikel yang direkat dengan urea formaldehida (UF) dapat mengganggu kesehatan, terutama jika digunakan di dalam ruangan dengan ventilasi terbatas. Untuk mengurangi emisi formal-dehida, produk tersebut dapat dilburi dengan suatu bahan kimia. Dalam tulisan ini dikemukakan pengaruh dari penggunaan pelaburan dengan amonium hidroksida $25 \%$ terhadap emisi formaldehida kayu lapis dan papan partikel yang masing-masing direkat dengan UF. Pengaruh pelaburan dengan amonium hidroksida terhadap emisi formaldehida kayu lapis dan papan partikel masing-masing sangat nyata. Semakin banyak amonium hidroksida yang dilaburkan, emisi formaldehida dari kayu lapis dan papan partikel sema-kin rendah. Pengaruh amonium hidroksida terhadap tingkat penurunan emisi formaldehida berbeda menurut jenis panel dan standar pengujian. Pada pelaburan dengan amonium hidroksida sebanyak $0,009 \mathrm{ml} / \mathrm{cm}^{2}$ dan 0,015 $\mathrm{ml} / \mathrm{cm}^{2}$, kayu lapis dan papan partikel memenuhi persyaratan emisi formaldehida Standar Jepang. Sedangkan pelaburan pada papan partikel sebanyak $0,003 \mathrm{ml} / \mathrm{cm}^{2}$, dan pada kayu lapis sebanyak $0,014 \mathrm{ml} / \mathrm{cm}^{2}$, emisi formaldehidanya memenuhi Standar Amerika.
\end{abstract}

Kata kunci : Kayu lapis, papan partikel, emisi formaldehida, pelaburan, amonium hidroksida

\section{PENDAHULUAN}

Kayu lapis dan papan partikel merupakan produk kayu yang dibuat dengan menggunakan perekat. Pada umumnya jenis perekat yang digunakan pada pembuatan produk tersebut adalah urea formaldehida. Perekat ini mempunyai kelemahan, yakni adanya emisi formaldehida dari produk yang direkat, yang dapat menimbulkan pencemaran terhadap lingkungan bilamana digunakan dalam ruangan yang relatif tertutup.

Sejak lama dipermasalahkan tentang batas emisi formaldehida, beberapa kalangan di Amerika menyebutkan batas emisi formaldehida adalah $0,330 \mathrm{mg} / \mathrm{L}$ dengan metode desikator 2 jam. Sedangkan Jepang, menginginkan kadar emisi formaldehida pada papan partikel dan kayu 
lapis rata - rata antara 0,5 - $5 \mathrm{mg} / \mathrm{l}$ dengan metode desikator 24 jam (Anonim, 1994).

Mengingat banyaknya kayu lapis dan papan partikel Indonesia yang di ekspor, maka produsen dituntut untuk melakukan upaya dalam menanggulangi emisi gas formaldehida. Beberapa upaya yang telah dilakukan antara lain dengan membuat komposisi perekat tertentu dengan penambahan bahan kimia yang berfungsi sebagai bahan penangkap. Penelitian mengenai pengurangan emisi formaldehida pada kayu lapis dan papan partikel telah dilakukan dengan cara pemberian bahan penangkap pada perekat, berupa urea dan melamin (Sutigno dan Santoso, 1995 dan 1996). Cara lain yang belum dilakukan adalah pelaburan. Mengingat hal itu perlu diteliti cara pelaburan dengan amonium hidroksida untuk mengurangi konsentrasi emisi formaldehida dari kayu lapis dan papan partikel. Menurut Hill (1960) reaksi antara formaldehida dengan amoniak dari amonium hidroksida membentuk heksametilentetramina (Urotropin) yang relatif stabil, dengan persamaan reaksi sebagai berikut:

$$
6 \mathrm{CHOH}+4 \mathrm{NH}_{3} \rightarrow \mathrm{C}_{6} \mathrm{H}_{12} \mathrm{~N}_{4}+6 \mathrm{H}_{2} \mathrm{O}
$$

Dalam tulisan ini dikemukakan pengaruh perlakuan banyaknya pelaburan amonium hidroksida terhadap kayu lapis dan papan partikel. Prinsip penelitian adalah penangkapan emisi formaldehida dari kayu lapis dan papan partikel oleh amoniak membentuk heksametilentetramina, selanjutnya formaldehida yang masih teremisi konsentrasinya dapat diukur dengan metode spektroskopi ultra violet.

Tujuan penelitian ini adalah untuk mendapatkan data tentang pengaruh pelaburan amonium hidroksida terhadap emisi gas formaldehida pada kayu lapis dan papan partikel, dengan sasaran mendapatkan jumlah minimum pelaburan untuk mengurangi emisi formaldehida dari kedua produk tersebut sehingga memenuhi persyaratan standar yang diinginkan.

\section{BAHAN DAN METODE}

\section{A. Bahan}

Kayu lapis (tebal $4 \mathrm{~mm}$ ) yang digunakan dalam penelitian ini diperoleh dari pasar, sedangkan papan partikel (tebal $12 \mathrm{~mm}$ ) diperoleh dari pabrik papan partikel Paparti di Sukabumi. Bahan kimia yang digunakan antara lain asam sulfat, asam kromotrofik, amonium asetat-asetil aseton, formaldehida $37 \%$, amonium hidroksida $25 \%$, asam asetat glasial, asam klorida, natrium sulfit, iod, timolftalin dan tiosulfat.

\section{B. Metode}

Pengambilan contoh kayu lapis dilakukan dengan pembelian yang ada di pasar, sedangkan papan partikel dilakukan dengan pembelian secara langsung dari pabrik papan partikel Paparti di Sukabumi. Lembar kayu lapis dan papan partikel yang berukuran $122 \mathrm{~cm} \times 244 \mathrm{~cm}$, diambil sebagai contoh secara acak dengan ukuran $40 \mathrm{~cm}$ x $40 \mathrm{~cm}$ masing - masing sebanyak 18 potong. Selanjutnya dari sejumlah tersebut diambil 6 potong untuk diberi perlakuan (masing - masing 3 potong untuk pengujian menurut standar Jepang dan standar Amerika).

Permukaan contoh yang diperoleh tersebut kemudian dilaburi dengan larutan amonium hidroksida 25\%. Setelah itu dilakukan penumpukan selama 24 jam dan pengukuran kadar air, setiap contoh produk tersebut dibuat contoh uji. Sebelum ditetapkan emisi formaldehidanya, masingmasing contoh uji dikondisikan dahulu selama 6 hari.

Penetapan emisi formaldehida dari masing - masing contoh produk dilakukan dengan dua macam standar, yaitu Standar Amerika (Anonim, 1983) dan Standar Jepang (Anonim, 2003). Menurut Standar Amerika, ukuran contoh uji adalah $13 \times 7$ $\mathrm{cm}$ dan banyaknya 8 buah. Sedangkan menurut Standar Jepang, ukuran contoh uji adalah 15 x $5 \mathrm{~cm}$ dan banyaknya 10 buah. Pembuatan contoh uji $1 \mathrm{~cm}$ dari tepi potongan contoh uji. 
Menurut Standar Amerika, pada bagian tepi contoh uji diberi lapisan parafin, kemudian dimasukkan ke dalam desikator yang telah berisi akuades dan dibiarkan selama 2 jam. Menurut Standar Jepang, contoh uji tidak diberi lapisan parafin melainkan langsung dimasukkan ke dalam desikator berisi akuades dan dibiarkan selama 24 jam. Alat yang dipakai untuk menetapkan banyaknya emisi formaldehida adalah spektrofotometer UV-Visibel Varian DMS-100 pada panjang gelombang $415 \mathrm{~nm}$.

Penelitian ini menggunakan rancangan acak lengkap (Sudjana, 1991) dengan percobaan faktorial, hubungan antara perlakuan dan respon yang diuji dinyatakan dengan garis regresi (Steel dan Torrie, 1989).

\section{HASIL DAN PEMBAHASAN}

Ikhtisar hasil penetapan emisi formaldehida dari kayu lapis dan papan partikel tercantum pada Tabel 1. Data ini merupakan rata - rata dari 5 ulangan.

Persyaratan emisi formaldehida untuk kayu lapis maupun papan partikel menurut Standar Amerika adalah 0,33 $\mathrm{mg} / \mathrm{L}$. Pada Tabel 1 terlihat bahwa setelah dilaburi dengan larutan amonium hidroksida $25 \%$ sebanyak $13,22 \times 10^{-3}$ $\mathrm{ml} / \mathrm{cm}^{2}$ emisi formaldehida kayu lapis memenuhi syarat, demikian pula pada papan partikel, setelah dilaburi dengan larutan yang sama menghasilkan emisi formaldehida yang memenuhi persyaratan.

Persyaratan emisi formaldehida untuk kayu lapis menurut Standar Jepang adalah sekitar 0,5 - $10 \mathrm{mg} / \mathrm{L}$ (JAS, 1982) dan antara 0,5-5,0 mg/L (JAS, 2000), sedangkan kadar emisi formaldehida papan partikel rata-rata antara $0,5-5 \mathrm{mg} / \mathrm{L}$. Pada Tabel 1 terlihat bahwa kayu lapis dan papan partikel yang dilaburi dengan larutan amonia $25 \%$ sebanyak $13,22 \times 10^{-3}$ $\mathrm{ml} / \mathrm{cm}^{2}$ emisi formaldehidanya memenuhi syarat.

Untuk mengetahui pengaruh konsentrasi pelaburan terhadap emisi formaldehida pada kayu lapis maupun papan partikel, dilakukan sidik ragam (Tabel 2) yang hasilnya menunjukkan bahwa perlakuan yang terdiri atas jumlah amonia, jenis panel dan standar uji yang diterapkan dalam penelitian ini berpengaruh sangat nyata, demikian pula interaksi antara satu perlakuan dengan perlakuan yang lainnya, kecuali interaksi antara standar uji dengan jenis panel yang tidak berpengaruh nyata.

Tabel 1. Emisi Formaldehida (mg/l) dari Kayu Lapis dan Papan Partikel

\begin{tabular}{ccccccc}
\hline Contoh & \multicolumn{3}{c}{ IHPA } & \multicolumn{3}{c}{ JIS } \\
\cline { 2 - 7 } & 1 & 2 & 3 & 1 & 2 & 3 \\
\hline Kayu Lapis & 5,654 & 1,319 & 0,324 & 19,552 & 6,336 & 1,536 \\
Papan Partikel & 1,822 & 0,347 & 0,087 & 12,720 & 8,352 & 5,152 \\
\hline Keterangan $: 1$ & $=$ Kontrol; & $2=6,61 \times 10^{-3} \mathrm{ml} \mathrm{cm}^{2} ; 3=13,22 \times 10^{-3} \mathrm{ml} / \mathrm{cm}^{2}$
\end{tabular}

Tabel 2. Ikhtisar Sidik Ragam Emisi Formaldehida

\begin{tabular}{ccc}
\hline Sumber keragaman & $\mathbf{F}_{\text {hitung }}$ & Keterangan \\
\hline Pelaburan, A & 85,94 & Sangat nyata \\
Standar uji, B & 110,97 & Sangat nyata \\
Jenis panel, C & 20,61 & Sangat nyata \\
Interaksi AB & 30,69 & Sangat nyata \\
Interaksi AC & 19,12 & Sangat nyata \\
Interaksi BC & 3,02 & - \\
Interaksi ABC & 6,17 & Sangat nyata \\
\hline
\end{tabular}


Bentuk hubungan antara faktor faktor yang berpengaruh tersebut ditentukan dengan menggunakan analisis regresi yang hasilnya menunjukkan bahwa hubungan regresi yang diperoleh sangat nyata dengan nilai kuadrat tengah $(\mathrm{KT})=$ $2.093,14$ dan $\mathrm{F}$ hitung $=21,70$. Bentuk persamaan regresi antara jumlah amonia dengan emisi formaldehida kayu lapis dan papan partikel masing-masing: $\mathrm{Y}_{\text {kayu lapis }}=$ $12,714-981,97 X, Y_{\text {papan partikel }}=7,0792-$ $352,47 \mathrm{X}$ dengan nilai koefisien korelasi $(\mathrm{r})=0,981$.

Berdasarkan persamaan tersebut terindikasi bahwa peningkatan jumlah amonia yang dilaburkan akan menurunkan emisi formaldehida, di mana penambahan $1 \mathrm{ml} / \mathrm{cm}^{2}$ amonia akan menurunkan emisi formaldehida kayu lapis sebesar 981,97 kali, sementara pada papan partikel sebesar 352,47 kali di banding kontrolnya. Hasil ini sejalan dengan hasil penelitian terdahulu di mana pemakaian amonium hidroksida pada panel kayu dapat menurunkan emisi formaldehida (Plath, 1967; Suhartini,1991) dan hasil penelitian Sundin (1980) dalam Jewell (1980) menunjukkan bahwa amoniak $\left(\mathrm{NH}_{3}\right)$ dari amonium hidroksida mampu mengurangi emisi formaldehida dari ikatan urea formaldehida pada produk kayu sampai 2/3-nya.

Berdasarkan persamaan regresi di atas dapat dikemukakan pula bahwa untuk konsentrasi yang sama, kayu lapis menyerap lebih banyak larutan amonium hidroksida $25 \%$ daripada papan partikel, hal ini diduga berhubungan erat dengan sifat higroskopisitas kedua produk tersebut, di mana kayu lapis pada umumnya memiliki higroskopisitas lebih besar daripada papan partikel, karena lebih dominan terdiri dari lembaran venir, sedangkan papan partikel kurang higroskopis karena pada umumnya mengandung parafin. Selain itu kerapatan kayu lapis pada umumnya lebih rendah daripada papan partikel, sehingga daya serapnya lebih tinggi. Hal tersebut sejalan dengan sinyalemen Christensen et al. (1981) yang mengemukakan bahwa selain kandungan formaldehida bebas dalam perekat, porositas panel sangat berpengaruh terhadap emisi formaldehida.

Untuk mendapatkan gambaran perbandingan pengaruh jumlah amonia terhadap emisi formaldehida pada setiap standar uji (IHPA dan JIS) dilakukan perhitungan regresi yang hasilnya sebagai berikut: $\mathrm{Y}_{\mathrm{IHPA}}=3,3586-267,22 \mathrm{X}$ dengan nilai koefisien korelasi $(\mathrm{r})=0,57$ dan $\mathrm{Y}_{\mathrm{JIS}}=$ 16,4346 - 1067,22X dengan nilai koefisien korelasi $(r)=0,81$. Persamaan regresi di atas menunjukkan bahwa emisi formaldehida pada produk kontrol yang diukur dengan metode IHPA lebih rendah dibandingkan dengan JIS. Hal ini mengindikasikan bahwa tahap kondisioning (7 hari) yang diberlakukan pada cara IHPA mengakibatkan sebahagian formaldehida bebas ke luar dari panel, sehingga pada saat pengujian emisi formaldehida dari panel lebih rendah, selain itu waktu pengumpulan formaldehida dalam metode JIS lebih lama (24 jam) dibandingkan dengan IHPA (2 jam), sehingga formaldehida yang terikat dalam media pengikat (air) lebih banyak.

Bila ditinjau pengaruh jumlah amonia terhadap emisi formaldehida kayu lapis dan papan partikel berdasarkan standar Amerika dan Jepang dengan pendekatan analisis regresi, diperoleh persamaan sebagai berikut :

$$
\begin{aligned}
\mathrm{Y}_{\mathrm{AK}} & =6,1760-403,17 \mathrm{X}, \mathrm{r}=0,56 \text { dan } \mathrm{Y}_{\mathrm{JK}} \\
& =19,2520-1560,77 \mathrm{X}, \mathrm{r}=0,98 \\
\mathrm{Y}_{\mathrm{AP}} & =0,5412-131,27 \mathrm{X}, \mathrm{r}=0,55 \text { dan } \mathrm{Y}_{\mathrm{JP}} \\
& =13,6172-573,67 \mathrm{X}, \mathrm{r}=0,79
\end{aligned}
$$

Di mana :

A = standar Amerika, $\mathbf{J}=$ standar Jepang

$\mathrm{K}=$ kayu lapis, $\mathrm{P}=$ papan partikel

Persamaan regresi di atas menggambarkan interaksi antara jumlah amonia, standar pengujian dan jenis panel. Berdasarkan persaan tersebut dapat dikemukakan bahwa pengukuran emisi formaldehida dengan cara IHPA pada kayu lapis, setiap penambahan amonia $1 \mathrm{ml} / \mathrm{cm}^{2}$ akan menurunkan emisi formaldehida sebesar 403,17 kali sementara dengan cara JIS adalah 573,67 kali. 


\section{KESIMPULAN DAN SARAN}

Pelaburan dengan amonium hidroksida $25 \%$ mampu menurunkan emisi formaldehida 982 kali pada kayu lapis, dan 352 kali papan partikel. Semakin banyak amonium hidroksida yang dilaburkan, emisi formaldehida dari kayu lapis dan papan partikel semakin rendah. Hubungan antara emisi formaldehida dengan kadar amonium hidroksida dapat dinyatakan dengan persamaan garis regresi linear.

Berdasarkan hasil penelitian, jumlah minimum amonium hidroksida $25 \%$ yang dilaburkan pada kayu lapis dan papan partikel sehingga emisi formaldehidanya memenuhi persyaratan standar Amerika berturut-turut adalah $0,0145 \mathrm{ml} / \mathrm{cm}^{2}$ dan $0,0035 \mathrm{ml} / \mathrm{cm}^{2}$, dan yang memenuhi persyaratan emisi formaldehida Standar Jepang, jumlah pelaburan minimum pada kayu lapis adalah $0,0091 \mathrm{ml} / \mathrm{cm}^{2}$ dan pada papan partikel $0,0150 \mathrm{ml} / \mathrm{cm}^{2}$.

Untuk memenuhi ketentuan emisi formaldehida kedua Standar, disarankan agar melakukan pelaburan dengan amonium hidroksida $25 \%$ pada kayu lapis maupun papan partikel masing-masing $13,22 \times 10^{-3} \mathrm{ml} / \mathrm{cm}^{2}$.

\section{DAFTAR PUSTAKA}

Anonim, 1983. Small Scale Test Method for Determining Formaldehyde from Wood Product, Two hours Desicator Test. National Particleboard Association, Maryland.

,1994. Japanese Industrial Standard. JIS A 5908-1994. Particle Boards Japanese Standard Association, Tokyo.

2003. Particleboards.JIS A 5908. Japanese Standard Association, Tokyo.

Cristensen, R., P Robichk and J Stone. 1981. Formaldehyde Emission from Particleboard. Hizz Als Roh und Werkstoff 39. pp: $231-134$.
Hill, Mc Graw. 1960. Formaldehyde In Encyclopedia of Science and Technology. Vol.5: 472-473.

Jewell, R. A. 1980. Reduction of formaldehyde levels in mobile home. Wood Adhesive Research, Application and Needs. Madison: 121-125.

Plath, L. 1967. Test of Formaldehyde Liberation from Particleboard Influence of Hardener Compounds on Formaldehyde Liberation. Holz Roch-Wekst 25(3), pp : $165-173$.

Sudjana, 1991. Disain dan Analisis Eksperimen. Tarsito, Bandung.

Suhartini. 1991. Pengaruh Fumigasi dan Penyemprotan

Steel RGD dan JH Torrie, 1989. Prinsip dan Prosedur Statistik. Gramedia, Jakarta

Sutigno P dan A. Santoso. 1995.Pengaruh penambahan urea dan melamin pada perekat urea formaldehida terhadap emisi formaldehida dan keteguhan rekat tripleks meranti. Jurnal Penelitian Hasil Hutan Vol. 13 (4): 144-152.

1996. Pengaruh penambahan urea dan melamin pada perekat urea fomaldehida terhadap emisi formaldehida dan sifat fisis-mekanis papan partikel. Buletin Penelitian Hasil Hutan Vol. 14 (5) : 178-191. 